\title{
The first Dutch SDHB founder deletion in paraganglioma - pheochromocytoma patients
} Jean-Pierre Bayley*1, Anneliese EM Grimbergen², Patrick A van Bunderen², Michiel van der Wielen ${ }^{2}$, Henricus P Kunst ${ }^{3}$, Jacques W Lenders ${ }^{5}$, Jeroen C Jansen ${ }^{3}$, Robin PF Dullaart ${ }^{6}$, Peter Devilee ${ }^{1}$, Eleonora P Corssmit ${ }^{4}$, Annette $\mathrm{H}$ Vriends ${ }^{2}$, Monique Losekoot ${ }^{2}$ and Marjan M Weiss ${ }^{2}$

\author{
Address: ${ }^{1}$ Department of Human Genetics, Leiden University Medical Center, Leiden, The Netherlands, ${ }^{2}$ Department of Clinical Genetics, Leiden \\ University Medical Center, Leiden, The Netherlands, ${ }^{3}$ Department of Otorhinolaryngology, Leiden University Medical Center, Leiden, The \\ Netherlands, ${ }^{4}$ Department of Endocrinology, Leiden University Medical Center, Leiden, The Netherlands, ${ }^{5}$ Department of Internal Medicine, \\ Radboud University Nijmegen Medical Center, Nijmegen, The Netherlands and ${ }^{6}$ Department of Endocrinology, University of Groningen and \\ University Medical Center Groningen, Groningen, The Netherlands \\ Email: Jean-Pierre Bayley* - j.p.l.bayley@lumc.nl; Anneliese EM Grimbergen - J.E.M.A.Grimbergen@lumc.nl; Patrick A van \\ Bunderen - P.A.van_Bunderen@lumc.nl; Michiel van der Wielen - M.J.R.van_der_Wielen@lumc.nl; Henricus P Kunst - H.Kunst@kno.umcn.nl; \\ Jacques W Lenders - j.lenders@aig.umcn.nl; Jeroen C Jansen - J.C.Jansen@lumc.nl; Robin PF Dullaart - r.p.f.dullaart@int.umcg.nl; \\ Peter Devilee - P.Devilee@lumc.nl; Eleonora P Corssmit - E.P.M.van_der_Kleij@lumc.nl; Annette H Vriends - A.H.J.T.Vriends@lumc.nl; \\ Monique Losekoot - M.Losekoot@lumc.nl; Marjan M Weiss - j.weiss@vumc.nl \\ * Corresponding author
}

Published: 15 April 2009

BMC Medical Genetics 2009, 10:34 doi:10.1 186/1471-2350-10-34
Received: 12 january 2009

Accepted: 15 April 2009

This article is available from: http://www.biomedcentral.com//47/-2350//0/34

(C) 2009 Bayley et al; licensee BioMed Central Ltd.

This is an Open Access article distributed under the terms of the Creative Commons Attribution License (http://creativecommons.org/licenses/by/2.0), which permits unrestricted use, distribution, and reproduction in any medium, provided the original work is properly cited.

\begin{abstract}
Background: Germline mutations of the tumor suppressor genes SDHB, SDHC and SDHD play a major role in hereditary paraganglioma and pheochromocytoma. These three genes encode subunits of succinate dehydrogenase (SDH), the mitochondrial tricarboxylic acid cycle enzyme and complex II component of the electron transport chain. The majority of variants of the SDH genes are missense and nonsense mutations. To date few large deletions of the SDH genes have been described.

Methods: We carried out gene deletion scanning using MLPA in 126 patients negative for point mutations in the SDH genes. We then proceeded to the molecular characterization of deletions, mapping breakpoints in each patient and used haplotype analysis to determine whether the deletions are due to a mutation hotspot or if a common haplotype indicated a single founder mutation.

Results: A novel deletion of exon 3 of the SDHB gene was identified in nine apparently unrelated Dutch patients. An identical 7905 bp deletion, c.201-4429_287-933del, was found in all patients, resulting in a frameshift and a predicted truncated protein, p.Cys68Hisfs X2I. Haplotype analysis demonstrated a common haplotype at the SDHB locus. Index patients presented with pheochromocytoma, extra-adrenal PGL and HN-PGL. A lack of family history was seen in seven of the nine cases.

Conclusion: The identical exon 3 deletions and common haplotype in nine patients indicates that this mutation is the first Dutch SDHB founder mutation. The predominantly non-familial presentation of these patients strongly suggests reduced penetrance. In this small series HN-PGL occurs as frequently as pheochromocytoma and extra-adrenal PGL.
\end{abstract}




\section{Background}

Paragangliomas occur as tumors of parasympathetically innervated head and neck paraganglia (HN-PGL), as intraabdominal and thoracic extra-adrenal paragangliomas of the sympathetic paraganglia, and as pheochromocytomas (PCC) of the adrenal medulla. Sympathetic paragangliomas may present clinically with hypertension, sweating and palpitations due to catecholamine excess, and especially in cases with extra-adrenal localization, they may be metastatic and aggressive. HN-PGL usually follows a mild course but may lead to significant morbidity due to compromised function of cranial nerves.

Although many paragangliomas are apparently sporadic (i.e. no known family history), many patients will carry a germline mutation, and worldwide up to $30 \%$ of all cases can be shown to have familial antecedents [1].

The identification in HN-PGL families of germline mutations of SDHD (succinate dehydrogenase, subunit D) [2] was soon followed by the identification of germline mutations in SDHB [3] and SDHC [4]. These three genes encode subunits of the mitochondrial tricarboxylic acid cycle enzyme, succinate dehydrogenase (SDH). SDH also acts as the complex II component of the electron transport chain, locating SDH at the center of cellular metabolism.

Despite the fact that SDH is thought to act solely as a unified protein complex, mutations of subunit genes lead to striking differences in clinical phenotype. While mutations of SDHD are associated predominantly with HNPGL, frequently multifocal and generally non-metastatic,SDHB mutation carriers frequently present with PCCs and extra-adrenal paragangliomas, and mutations of $S D H B$ are more often found in patients with aggressive, metastatic disease [5]. Until recently mutations of SDHC were exclusively associated with HN-PGL, but have now also been identified in patients with PCC $[6,7]$.

The majority of mutations of the SDH genes described in the SDH mutation database [8] http://chromium.liacs.nl/ lovd $\mathrm{sdh} /$ home.php are missense and nonsense mutations $(n=225)$. To date only ten distinct large deletions of the SDH genes have been described.

Although nearly all familial paraganglioma in the Netherlands is accounted for by the Dutch SDHD founder mutations p.Asp92Tyr and p.Leu139Pro [9], several Dutch families carrying an $S D H B$ mutation were recently identified [10]. Here we describe the results of SDHB gene deletion scanning of 126 paraganglioma-PCC patients. Nine apparently unrelated Dutch patients all showed deletions of exon 3 of the SDHB gene. In order to determine if exon 3 is affected by a deletion hotspot, we proceeded to the molecular characterization of the deletion, mapping the breakpoint in each patient, and used haplotype analysis to determine whether the patients share any common haplotype, which would suggest a single novel founder mutation. In addition, the clinical phenotype of these patients is described.

\section{Methods \\ Patients}

Between 2000 and 2008, a total of 251 index patients with either a paraganglioma or PCC were referred for molecular testing of the $S D H D / B / C$ genes to the Molecular Genetics Laboratory at the Leiden University Medical Center, The Netherlands. Informed consent was obtained for DNA testing according to protocols approved by LUMC Ethics Review Board. DNA was available from 126 index patients who tested negative for SDHD point mutations and in whom point mutations of SDHB and SDHC were, in most cases, also excluded.

\section{Multiplex ligation dependent probe amplification}

MLPA was carried out with the P226 MLPA kit http:// www.mrc-holland.com, containing probes for all exons of the SDHB, SDHC and SDHD genes, as well as probes located in the promoter of each gene (27 different probes). MLPA analysis was performed according to the MRC Holland protocol [11] except that all reagents in the kit were used at $1 / 2$ of the recommended volume and hybridization time was reduced from 16 to 2.5 hours. No difference in results was seen compared to recommended conditions.

\section{Haplotype analysis}

Analysis of haplotypes by polymorphic di- and tetra nucleotide markers (microsatellite markers) was performed according to standard procedures (details available upon request), using the following markers: D1S436, D1S2697, D1S170, D1S3669, D1S2826 and D1S2644. The distance between the last and the first marker is $~ 3.35$ $\mathrm{Mb}$. In addition, intragenic SNPs were sequenced to refine the haplotype (Table 1 ). The frequency of marker alleles in the Dutch population was determined in 24 healthy controls.

\section{Breakpoint characterization}

Long range PCR using the primers F2 (5'-TCT GTT GTG CCA GCA AAA TG-3') and R4 (5'-CAA ATC CTG CCC TGA AAA AC-3') was carried out using the Takara LA Taq kit (Takara Bio Inc., Lucron Bioproducts B.V., Gennep, The Netherlands) following the manufacturers recommendations. The resulting PCR fragment of $8.5 \mathrm{~kb}$ in the patients carrying the deletion was subjected to restriction mapping using the following twelve enzymes: Alw44I, BglI, BglII, BsaHI, BspEI, EcoRI, Mph1103I, NdeI, SacI, ScaI, SmaI, $X b a I$. Analysis of the resulting restriction patterns narrowed the specific region of the deletion, and was followed by the design of primers 2162 (5'-CCA GTC CAT GAA AGG CAA-3') and 2164 (5'-GCT CCA TGT GTC ACG 
Table I: Name and physical location of chromosome I microsatellite markers and intragenic SNPs used for haplotyping

\begin{tabular}{|c|c|}
\hline Marker name (in chromosomal order) & Chromosomal location (UCSC Genome Browser. Human Mar. 2006 Assembly) \\
\hline DIS436 & 15643044 \\
\hline DIS2697 & 16192037 \\
\hline DISI70 & 17070023 \\
\hline SDHB gene & 17217812 \\
\hline rs 12045097 & 17218463 \\
\hline rs287I775 & $|72| 849 \mid$ \\
\hline rs978528 & 17222384 \\
\hline rs2235931 & $|722254|$ \\
\hline rs2235930 & 17222729 \\
\hline rs2647162 & 17222829 \\
\hline rs 12142244 & 17223517 \\
\hline rs2235929 & 17223682 \\
\hline rs7550829 & 17230163 \\
\hline rs2746467 & $1723020 \mid$ \\
\hline rsII57707| & $1723 \mid 760$ \\
\hline rs4920390 & $1723 \mid 880$ \\
\hline rs 10887990 & 17231972 \\
\hline rsII203284 & 17242538 \\
\hline rs II 203285 & 17242706 \\
\hline rs 10887992 & 17242799 \\
\hline rs 10887993 & 17242827 \\
\hline \multicolumn{2}{|l|}{ c. $200+987 C>T$} \\
\hline rs II 203287 & 17244983 \\
\hline rs9435747 & 17245053 \\
\hline rsII582579 & 17245097 \\
\hline rs6690934 & 17245208 \\
\hline rs7536679 & 17247249 \\
\hline rs7545499 & 17247274 \\
\hline
\end{tabular}


Table I: Name and physical location of chromosome I microsatellite markers and intragenic SNPs used for haplotyping (Continued)

\begin{tabular}{cc}
\hline rs7545518 & 17247328 \\
\hline SDHB gene & 17253252 \\
\hline DIS3669 & 17556185 \\
\hline DIS2826 & 18205820 \\
\hline DIS2644 & 18799054
\end{tabular}

TGT TT-3'). This allowed the amplification of a $1.6 \mathrm{~kb}$ fragment in patients carrying the deletion but not in healthy controls. The PCR product was sequenced, and analyzed using the Multalin program http://bio info.genopole-toulouse.prd.fr/multalin/multalin.html.

Sequence analysis of the $S D H B$ gene was performed according standard procedures (details available upon request), using the NT_004610.18 reference sequence.

\section{Results}

\section{MLPA analysis}

MLPA allows the detection of large deletions, and is based on the quantification of multiplexed amplified DNA fragments. It was first described by Schouten et al. in 2002 [11] and due to reliability and ease of use has been widely adopted in both research and diagnostic settings.
All 251 index patients were screened for germline mutations in SDH genes by sequence analysis. A pathogenic mutation was identified in 125 patients (50\%). MLPA analysis was performed in 126 mutation negative patients, and included all exons and the promoter of the $S D H B, S D H C$ and SDHD genes. Deletions of the SDHB gene were detected in nine patients, all affecting exon 3 (figure 1). Four deletions were identified in the SDHC and SDHD genes and will be described elsewhere. In the entire series 13 of 251 patients (5\%) were found to have deletions, representing approximately $10 \%$ of all mutations found. To further characterize the $S D H B$ deletions and confirm the MLPA results, a long range PCR flanking exon 3 was designed. While the expected normal fragment ( 16 $\mathrm{kb}$ ) could barely be detected, all patients carrying exon 3 deletions showed a shorter fragment of $\sim 9 \mathrm{~kb}$ (figure 2 ).

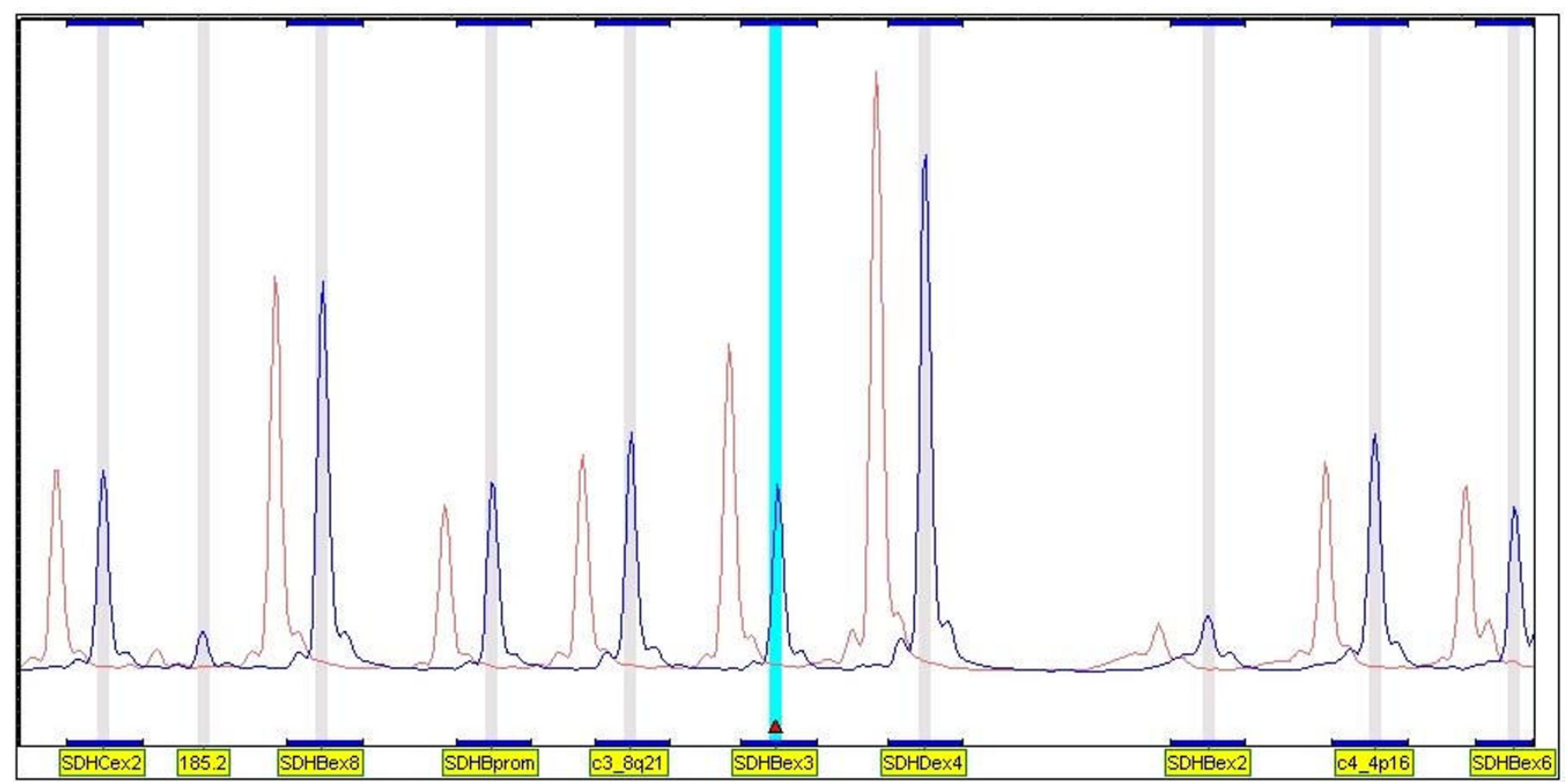

Figure I

An example of MLPA analysis of the SDHB, SDHC and SDHD genes. Only some exons of each gene can be seen in this view but all are included in the kit (P226 MLPA kit), plus the promoters of each gene, and several control fragments located on various chromosomes. Red peaks show the average of normal control DNA and blue peaks represent the DNA of the patient. The deletion of exon 3 of SDHB can clearly be seen (small red diamond). 


\section{Breakpoint characterization}

Restriction mapping of the $9 \mathrm{~kb} S D H B$ fragment was carried out using twelve enzymes. Analysis of restriction patterns narrowed the breakpoints to small regions of intron 2, approximately $4.5 \mathrm{~kb}$ upstream of exon 3 and to a region $3.5 \mathrm{~kb}$ downstream, in intron 3 . Primers were designed around the expected site of the deletion, and a $1.6 \mathrm{~kb}$ fragment could be amplified in all patients carrying the deletion, indicating that all deletions were either identical or mapped to a small and specific region, which would suggest a mutation hotspot.

Sequencing of the $1.6 \mathrm{~kb}$ PCR product revealed identical breakpoints in all samples, resulting in a deletion of 7905 bp, including exon 3 (figure 3), suggesting a single founder mutation, identical by descent. Following HGVS cDNA nomenclature, the deletion is correctly described as c.201-4429_287-933del. The deletion of exon 3 is predicted to result in a frameshift at the DNA level and a truncated protein, p.Cys68HisfsX21.

Although analysis of the surrounding sequence revealed that the upstream breakpoint is located in an AluSz repeat, the downstream breakpoint is located in unique sequence, rather than in an Alu repeat. Thus there are no repeat sequences or sequence similarity around the breakpoint that would suggest a mechanism of deletion or location of a mutational hotspot.

\section{Haplotype analysis}

Although the patients had no apparent family connection, all are natives of the Netherlands and share an identical SDHB deletion.

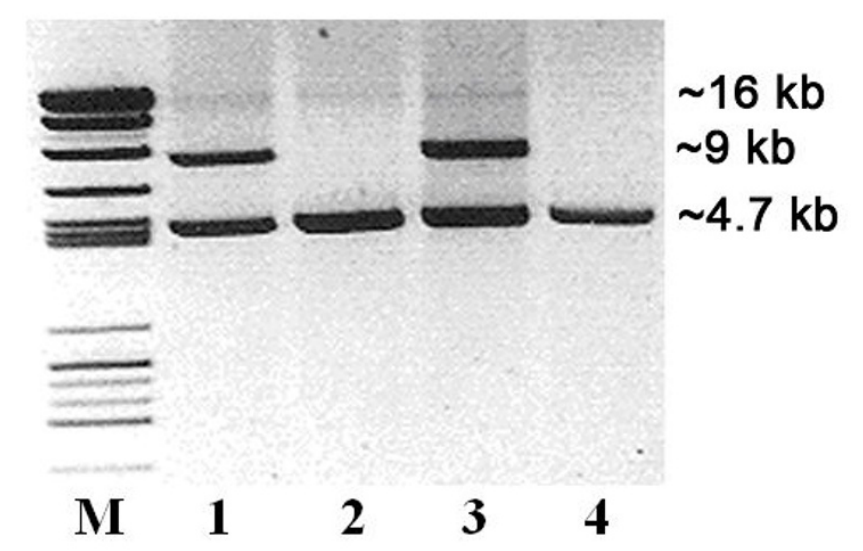

Figure 2

Long range PCR of the exon 3 region of SDHB. Lanes I \& 3. Patients carrying deletions showed an anomalous fragment of $\sim 9 \mathrm{~kb}$. Lanes $2 \& 4$. Two healthy controls lack the anomalous $\sim 9 \mathrm{~kb}$ fragment. The normal fragment $(\sim 16 \mathrm{~kb})$ is weakly visible in all lanes. A PCR control fragment of $\sim 4.7 \mathrm{~kb}$ is also visible in all lanes.
Therefore we carried out haplotype analysis with six diand tetra nucleotide polymorphic markers surrounding the $S D H B$ gene. Haplotyping was refined by typing additional intragenic SNPs. A common haplotype could be deduced in all patients (figure 4), indicating descent from a common ancestor. The marker haplotype formed by D1S436, D1S2697, and D1S170 has a frequency of 1\% in the Dutch population, and the likelihood of nine unrelated cases carrying this haplotype is $\sim 1.4 \times 10^{-18}$. Certain haplotypes have apparently mutated or recombined in selected patients, an indication that they are only distantly related.

\section{Clinical data}

Patient BD1 presented with a hard mass in the neck at 41 years of age, initially suspected to be an aneurysm, but no other symptoms. MRI imaging revealed a large and highly vascular mass, $4 \times 2 \mathrm{~cm}$, at the carotid bifurcation, partially displacing the larynx. A second tumor was visible above the primary mass, apparently a secondary process of the carotid body tumor. Biopsy and pathological evaluation confirmed the diagnosis.

Patient BD2 was diagnosed with both a malignant extraadrenal paraganglioma and a parathyroid tumor at the age of 60 . The patient's brother was diagnosed at the age of 50 with a PCC, and their mother had possibly been treated for a malignant PCC.

Patient BD3 presented at the age of 35 with a right sided jugulotympanic paraganglioma, in combination with raised dopamine levels. MRI of the head and neck revealed no further tumors. A partial resection was carried out in 2007, following complaints of reduced hearing and tinnitus. MRI of the head and neck revealed no further tumors. Although increased urinary dopamine excretion indicated a possible occult sympathetic paraganglioma, MRI of the thorax and abdomen revealed no further tumors. The patient had a negative family history.

Patient BD4 presented with a retroperitoneal paraganglioma directly under the diaphragm and a paraganglioma of the urinary bladder at the age of 28 . No other tumors were found. A recent MRI scan, nine years after the initial treatment, revealed no further tumors. The patient had a clinically negative family history, and although the patient's mother also has the mutation, she remains unaffected at the age of 66 .

A female patient BD5, presented with bilateral carotid body paraganglioma at 51 yrs, and 15 years later the patient was found to have raised urine normetanephrine and dopamine levels. In addition to visualization of the largest left-sided carotid body paraganglioma by ${ }^{111}$ Inoctreotide scintigraphy, DOPA-PET and FDG PET-scanning revealed a suspicious lesion in the abdomen, suggest- 


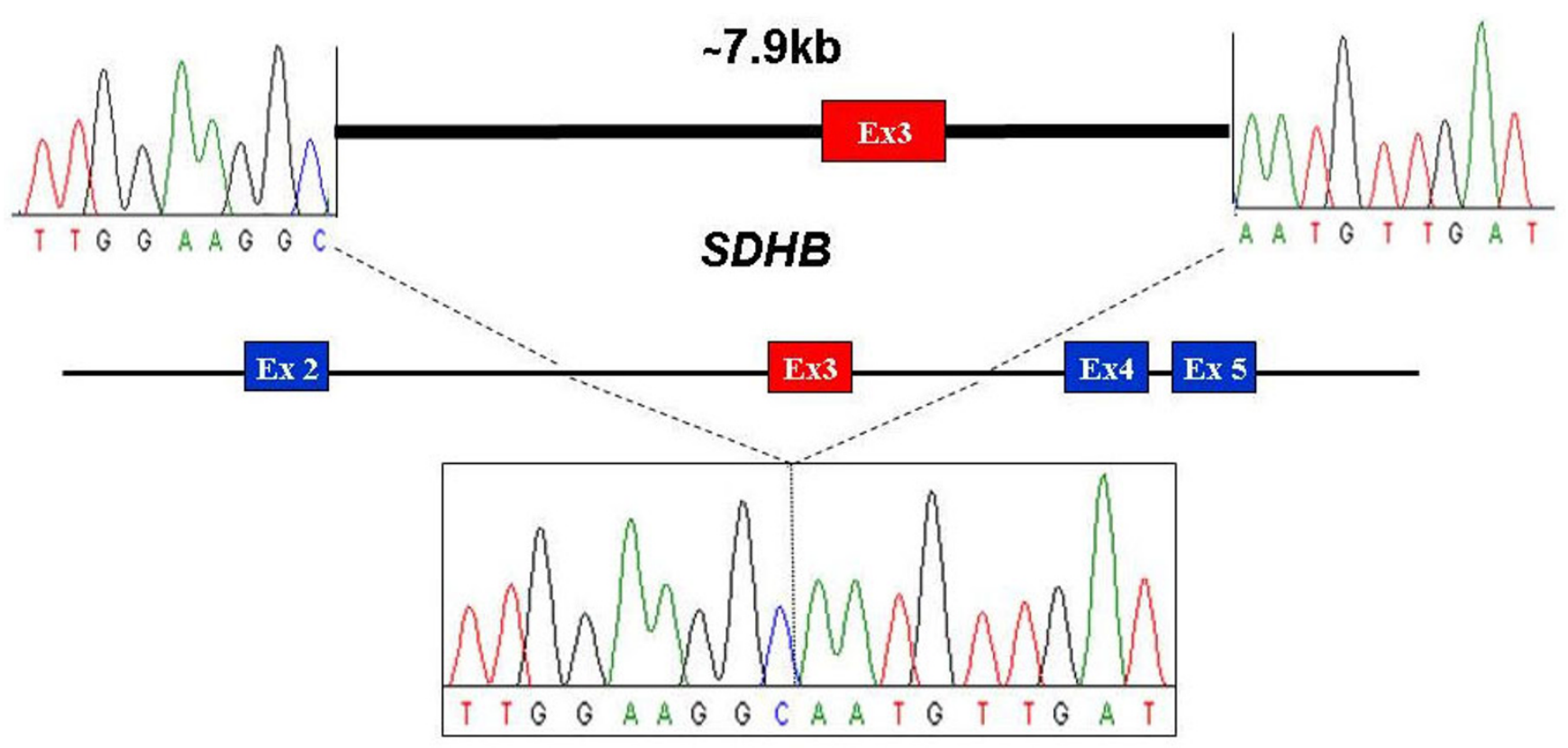

Breakpoint

Figure 3

Characterization of the exon 3 SDHB breakpoint. The lower box shows a patient sequence spanning the deletion. The upper figure indicates the approximate location of each portion of the sequence in respective introns in the normal undeleted gene sequence.

ing co-existing extra-adrenal paraganglioma. Due to the risk of co-morbidity, the lesions are being followed conservatively.

Patient BD6 presented with a malignant extra-adrenal paraganglioma with bone metastases at the age of 12, and a pituitary tumor. The paternal grandfather is known to have had a pituitary tumor. The family history is negative for paraganglioma.

Patient BD7, a 55-year old male, presented with a left sided carotid body paraganglioma, which was resected at the age of 50. To date there is no increased excretion of urinary catecholamine's or their O-methylated metabolites. A recent MRI of the thorax and abdomen revealed no additional paragangliomas. No family history was available.

Patient BD8 presented with a jugulotympanic paraganglioma at the age of 18 . Recently, at the age of 51 years, MRI of the head and neck and CT of the thorax revealed that the patient had developed no further tumors. No clear family history was available.

Patient BD9 was recently diagnosed, at the age of 28, with a retroperitoneal presacral paraganglioma without raised catecholamine levels. MIBG, DOPA-PET and FDG of the head, neck and thorax revealed no further tumors. The family history is negative.

Clinical details for all nine patients are shown in overview (Table 2).

\section{Discussion}

While the majority of SDH-related hereditary HN-PGL and PCC patients carry missense and nonsense mutations, a significant proportion of patients may carry whole gene or exon deletions. In the entire current series of patients 13 of 251 (5\%) were found to have deletions, representing $10 \%$ of all mutations found. These data have clear implications for diagnostic DNA screening and indicate that deletion scanning such as MLPA should be considered once patients have tested negative by sequencing.

Ten deletions affecting SDH genes have been described to date. McWhinney et al. first described deletions of $S D H B$ and SDHD in two families in 2004 [12]. While a large SDHD deletion was associated with HN-PGL in one family, a deletion of exon 1 of $S D H B$ in a Brazilian family resulted in extra-adrenal PGL, together with HN-PGL. Baysel et al. described a family carrying a deletion affecting exon 6 of $S D H C$, and including five affected members, all with $\mathrm{HN}$ PGL [13]. Cascon et al. subsequently described deletions of $S D H B$ in families from the Iberian peninsula, [14] identify- 


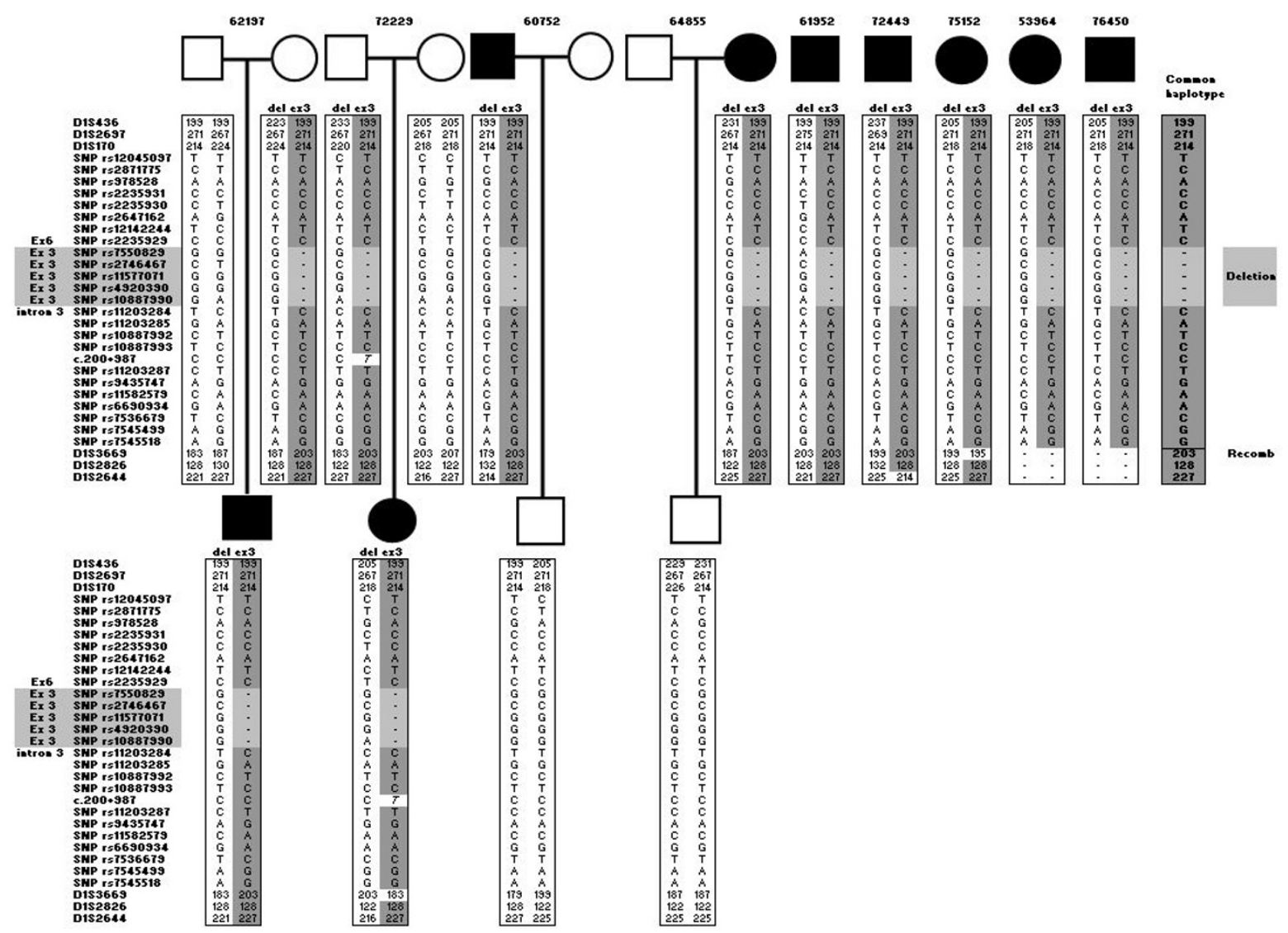

Figure 4

Haplotype analysis of patients carrying the SDHB exon 3 deletion. Microsatellites flanking SDHB and intragenic SNPs demonstrate a common haplotype. The common haplotype and the region deleted are indicated.

ing the first whole gene deletion of $S D H B$ and a deletion of exon 1 . This latter deletion was shown to be a founder on further characterization and an additional unique exon 1 deletion was identified in a French family [15]. These patients showed predominantly retroperitoneal PGL, but two cases from the French family developed adrenal PCC.

Amar et al. have recently described a novel deletion of $S D H B$ in a patient studied in relation to metastatic paraganglioma [16]. This deletion was not further characterized. Fish et al. reported a mixed picture of both HN-PGL and extra-adrenal PGL in a family with a deletion of exon 3 of SDHD [17]. Pasini et al. have described a patient who presented at 9 years of age with multiple GISTs, and by the age 16 had developed multiple retroperitoneal paragangliomas. This patient showed a large deletion affecting $S D H B$, but as no tumor material was available, the relation of $S D H B$ to the GIST could not be demonstrated [18]. Pigny et al. have reported a deletion of SDHB exons $7 \& 8$ in a patient with bilateral pheochromocytoma [19].

The clinical features of the SDHB exon 3 deletion patients described in this report differ from most of the reports described above in the higher than expected frequency of
HN-PGL. Previous studies have shown that SDHB mutations predominantly predispose to abdominal or thoracic paragangliomas and adrenal PCC [20], but as Leiden is a national referral centre for HN-PGL, a referral bias may be operating.

Although relatively few deletions have thus far been described, the current picture does not indicate that the phenotype caused by deletions differs substantially from that of missense and nonsense mutations. While mutations of $S D H B$ and $S D H D$ show an intriguing divergence in related phenotypes despite the intimate association of the protein subunits, gene deletions are unlikely to show specific genotype-phenotype effects, relative to truncating or missense mutations, because all mutations are assumed to result in loss of protein function.

The best current estimates of penetrance for $S D H B$ mutations are $77 \%$ at 50 years [20] and approximately $60 \%$ at 50 yrs [5]. These figures are based largely on index cases, as few patients present in the context of extended families. Such estimates are known to exaggerate penetrance, and more accurate estimates will require large SDHB-related families, and the inclusion and detailed clinical screening 
Table 2: Clinical summary of patients and family members with the SDHB exon 3 deletion

\begin{tabular}{|c|c|c|c|c|}
\hline Patient ID & Age at Diagnosis & Gender & Family Clinical History & Clinical Features \\
\hline BDI & 41 & Female & Negative & Carotid body paraganglioma, left \\
\hline BD2 & NA & Female & Mother \& brother with pheochromocytoma & $\begin{array}{l}\text { Extra adrenal pheochromocytoma } \\
\text { Parathyroid tumor }\end{array}$ \\
\hline BD3 & 35 & Male & Negative & $\begin{array}{l}\text { Jugulotympanic paraganglioma with raised } \\
\text { catecholamine levels. No evidence of } \\
\text { pheochromocytoma }\end{array}$ \\
\hline BD4 & 28 & Male & Negative & $\begin{array}{l}\text { Retroperitoneal paraganglioma and paraganglioma of } \\
\text { the urinary bladder }\end{array}$ \\
\hline BD5 & 51 & Female & NA & $\begin{array}{l}\text { Bilateral carotid body paraganglioma. Raised urine } \\
\text { normetanephrine and dopamine levels, possible } \\
\text { extra-adrenal paraganglioma }\end{array}$ \\
\hline BD6 & 12 & Female & Negative & $\begin{array}{l}\text { Malignant extra-adrenal paraganglioma with bone } \\
\text { metastases. Pituitary tumor. Paternal grandfather had } \\
\text { pituitary tumor. }\end{array}$ \\
\hline BD7 & 50 & Male & Negative & Carotid body paraganglioma, left \\
\hline BD8 & 18 & Female & NA & Jugulotympanic paraganglioma \\
\hline BD9 & 28 & Male & NA & Retroperitoneal paraganglioma \\
\hline
\end{tabular}

of apparently unaffected mutation carriers in addition to patients.

The only large family described to date [21] suggests a much lower penetrance but there was no detailed clinical screening of mutation carriers and the authors made no attempt to estimate penetrance. The fact that $S D H B$ germline mutation carriers often present as apparently nonfamilial cases has not escaped various authors [5,22-24] and even proven founder mutations of $S D H B$ may initially present as isolated families [15] (and this study).

In contrast, $S D H D$-related mutations show a very high penetrance, over $80 \%$ at 50 years [5], and also show a striking and unique imprinted or parent-of-origin inheritance [25], showing almost complete penetrance with paternal inheritance, while mutation carriers via the maternal line remain tumor-free throughout life. This is in sharp contrast with the SDHB and SDHC genes, located on chromosome 1, which do not show parent-of-origin inheritance. All evidence indicates that it is not the SDHD gene itself which is imprinted $[2,26]$ but that some additional locus on chromosome 11 is involved.

The major imprinted locus of the human genome is on chromosome 11p15.5, and we have proposed a model in which an imprinted and maternally expressed gene on chromosome 11p15.5 must be lost together with the nor- mal maternal SDHD allele (the paternal allele is inactivated by a germline mutation) prior to initiation of tumorigenesis [26]. This mechanism, recently referred to as the 'Hensen model' [27], is supported by additional data for chromosome 11 [28] and may also play a role in chromosome 3-linked VHL PCC $[29,30]$.

This model could provide a genetic explanation for the reduced penetrance of $S D H B$ mutations, in which both $S D H B$ and the modifier must be lost, requiring loss on two separate chromosomes; intrinsically less likely than a single genetic event (whole chromosome loss) which has been shown to be the mechanism in SDHD tumors $[26,28]$. Alternatively or additionally, the difference in penetrance may have a (partly) biochemical explanation, related to the difference in function of the SDHD and SDHB subunits, the former principally structural, the latter catalytic. A unique biochemical effect of $S D H B$ mutations seems likely in the light of the differing location and often aggressive behavior of tumors, and the high number of clinically penetrant mutations identified. No current model of PGL tumorigenesis can explain these phenomena $[31,32]$.

\section{Conclusion}

We describe the first Dutch founder mutation of $S D H B$, a novel deletion of exon 3. Index patients presented with PCC, extra-adrenal PGL as well as HN-PGL. Lack of a clear 
family history in seven out of nine cases strongly indicates reduced penetrance. Family studies will be extended to further delineate penetrance and expression.

\section{Competing interests}

The authors declare that they have no competing interests.

\section{Authors' contributions}

JPB collected and analyzed the data, co-designed the study, and wrote the manuscript. MMW and ML edited and analyzed the data, co-designed the study, and cowrote the manuscript. AHV, EPC, and PD designed and implemented the study, and contributed to the manuscript. AEMG, PB, MW, HPK, JJ, JWL, RPFD and GPWG collected and analyzed the data. All authors read and approved the final manuscript.

\section{Acknowledgements}

We would like to thank the patients and their families for their cooperation. This work was partly carried out by Michiel Helmond (student). This research was supported by the Dutch Cancer Society (Grant UL 20022723) and the European Union 6 th Framework Program (Project No: 518200). Dr. Robin PF Dullaart represents the Groningen Paraganglioma Working Group (GPWG), Department of Endocrinology, Dr TP Links, Dr ANA van der Horst).

\section{References}

I. Neumann HP, Bausch B, McWhinney SR, Bender BU, Gimm O, Franke $\mathrm{G}$, et al.: Germ-line mutations in nonsyndromic pheochromocytoma. N Engl J Med 2002, 346: |459-|466.

2. Baysal BE, Ferrell RE, Willett-Brozick JE, Lawrence EC, Myssiorek D, Bosch A, et al:: Mutations in SDHD, a mitochondrial complex II gene, in hereditary paraganglioma. Science 2000, 287:848-85I.

3. Astuti D, Latif F, Dallol A, Dahia PL, Douglas F, George E, et al.: Gene mutations in the succinate dehydrogenase subunit SDHB cause susceptibility to familial pheochromocytoma and to familial paraganglioma. Am J Hum Genet 200I, 69:49-54.

4. Niemann S, Muller U: Mutations in SDHC cause autosomal dominant paraganglioma, type 3. Nat Genet 2000, 26:268-270.

5. Benn DE, Gimenez-Roqueplo AP, Reilly JR, Bertherat J, Burgess J, Byth $\mathrm{K}$, et al.: Clinical presentation and penetrance of pheochromocytoma/paraganglioma syndromes. J Clin Endocrinol Metab 2006, $91: 827-836$.

6. Mannelli M, Ercolino T, Giache V, Simi L, Cirami C, Parenti G: Genetic screening for pheochromocytoma: should SDHC gene analysis be included? J Med Genet 2007, 44:586-587.

7. Peczkowska M, Cascon A, Prejbisz A, Kubaszek A, Cwikla BJ, Furmanek $M$, et al.: Extra-adrenal and adrenal pheochromocytomas associated with a germline SDHC mutation. Nat Clin Pract Endocrinol Metab 2008, 4: I I I-I I5.

8. Bayley JP, Devilee P, Taschner PE: The SDH mutation database: an online resource for succinate dehydrogenase sequence variants involved in pheochromocytoma, paraganglioma and mitochondrial complex II deficiency. BMC Med Genet 2005, 6:39.

9. Taschner PE, Jansen JC, Baysal BE, Bosch A, Rosenberg EH, BrockerVriends $\mathrm{AH}$, et al: Nearly all hereditary paragangliomas in the Netherlands are caused by two founder mutations in the SDHD gene. Genes Chromosomes Cancer 200I, 3 I:274-28I.

10. Bayley JP, van MI, Weiss MM, Jansen JC, Oomen PH, Menko FH, et al.: Mutation analysis of SDHB and SDHC: novel germline mutations in sporadic head and neck paraganglioma and familial paraganglioma and/or pheochromocytoma. BMC Med Genet 2006, 7:I.

II. Schouten JP, McElgunn CJ, Waaijer R, Zwijnenburg D, Diepvens F, Pals G: Relative quantification of 40 nucleic acid sequences by multiplex ligation-dependent probe amplification. Nucleic Acids Res 2002, 30:e57.

12. McWhinney SR, Pilarski RT, Forrester SR, Schneider MC, Sarquis MM, Dias EP, et al.: Large germline deletions of mitochondrial complex II subunits SDHB and SDHD in hereditary paraganglioma. J Clin Endocrinol Metab 2004, 89:5694-5699.

13. Baysal BE, Willett-Brozick JE, Filho PA, Lawrence EC, Myers EN, Ferrell RE: An Alu-mediated partial SDHC deletion causes familial and sporadic paraganglioma. J Med Genet 2004, 4 I:703-709.

14. Cascon A, Montero-Conde C, Ruiz-Llorente S, Mercadillo F, Leton R, Rodriguez-Antona C, et al.: Gross SDHB deletions in patients with paraganglioma detected by multiplex PCR: a possible hot spot? Genes Chromosomes Cancer 2006, 45:213-219.

15. Cascon A, Landa I, Lopez-Jimenez E, ez-Hernandez A, Buchta M, Montero-Conde $\mathrm{C}$, et al: Molecular characterisation of a common SDHB deletion in paraganglioma patients. J Med Genet 2008, 45:233-238.

16. Amar L, Baudin E, Burnichon N, Peyrard S, Silvera S, Bertherat J, et al.: Succinate dehydrogenase $B$ gene mutations predict survival in patients with malignant pheochromocytomas or paragangliomas. J Clin Endocrinol Metab 2007, 92:3822-3828.

17. Fish JH, Klein-Weigel P, Biebl M, Janecke A, Tauscher T, Fraedrich G: Systematic screening and treatment evaluation of hereditary neck paragangliomas. Head Neck 2007, 29:864-873.

18. Pasini B, McWhinney SR, Bei T, Matyakhina L, Stergiopoulos S, Muchow $M$, et al.: Clinical and molecular genetics of patients with the Carney-Stratakis syndrome and germline mutations of the genes coding for the succinate dehydrogenase subunits SDHB, SDHC, and SDHD. Eur J Hum Genet 2008, 16:79-88.

19. Pigny P, Cardot-Bauters C, Do CC, Vantyghem MC, Carnaille B, Pattou $F$, et al: Should genetic testing be performed in each patient with sporadic pheochromocytoma at presentation? Eur J Endocrinol 2009, 160:227-231.

20. Neumann HP, Pawlu C, Peczkowska M, Bausch B, McWhinney SR, Muresan $M$, et al.: Distinct clinical features of paraganglioma syndromes associated with SDHB and SDHD gene mutations. JAMA 2004, 292:943-95I

21. McDonnell CM, Benn DE, Marsh DJ, Robinson BG, Zacharin MR: K40E: a novel succinate dehydrogenase (SDH)B mutation causing familial phaeochromocytoma and paraganglioma. Clin Endocrinol (Oxf) 2004, $61: 510-514$

22. Baysal BE, Willett-Brozick JE, Lawrence EC, Drovdlic CM, Savul SA McLeod DR, et al:: Prevalence of SDHB, SDHC, and SDHD germline mutations in clinic patients with head and neck paragangliomas. J Med Genet 2002, 39:178-183.

23. Young AL, Baysal BE, Deb A, Young WF Jr: Familial malignant catecholamine-secreting paraganglioma with prolonged survival associated with mutation in the succinate dehydrogenase B gene. J Clin Endocrinol Metab 2002, 87:4I0I-4I05.

24. Timmers HJ, Kozupa A, Eisenhofer G, Raygada M, Adams KT, Solis D, et al: Clinical presentations, biochemical phenotypes, and genotype-phenotype correlations in patients with succinate dehydrogenase subunit B-associated pheochromocytomas and paragangliomas. I Clin Endocrinol Metab 2007, 92:779-786.

25. Mey AG Van Der, Maaswinkel-Mooy PD, Cornelisse CJ, Schmidt PH, Kamp JJ van de: Genomic imprinting in hereditary glomus tumours: evidence for new genetic theory. Lancet 1989 , 2: $129 \mid-1294$

26. Hensen EF, Jordanova ES, van Minderhout IJHM, Hogendoorn PCW, Taschner PEM, Mey AGL van der, et al.: Somatic loss of maternal chromosome I I causes parent-of-origin-dependent inheritance in SDHD-linked paraganglioma and phaeochromocytoma families. Oncogene 2004, 23:4076-4083.

27. Pigny P, Vincent A, Cardot BC, Bertrand M, de MV, Crepin M, et al.: Paraganglioma after maternal transmission of a succinate dehydrogenase gene mutation. J Clin Endocrinol Metab 2008, 93:1609-1615.

28. Riemann K, Sotlar K, Kupka S, Braun S, Zenner HP, Preyer S, et al.: Chromosome I I monosomy in conjunction with a mutated SDHD initiation codon in nonfamilial paraganglioma cases. Cancer Genet Cytogenet 2004, I 50: I 28- 135.

29. Mircescu H, Wilkin F, Paquette J, Oligny LL, Decaluwe H, Gaboury L, et al: Molecular characterization of a pediatric pheochromo- 
cytoma with suspected bilateral disease. J Pediatr 200I, I38:269-273.

30. Margetts CDE, Astuti D, Gentle DC, Cooper WN, Cascon A, Catchpoole D, et al: Epigenetic analysis of HICI, CASP8, FLIP, TSPI, DCR I, DCR2, DR4, DR5, KvDMR I, HI 9 and preferential IIpI5.5 maternal-allele loss in von Hippel-Lindau and sporadic phaeochromocytomas. Endocrine-Related Cancer 2005, 12:161-172.

31. Gottlieb E, Tomlinson IP: Mitochondrial tumour suppressors: a genetic and biochemical update. Nat Rev Cancer 2005, 5:857-866.

32. Lee S, Nakamura E, Yang H, Wei W, Linggi MS, Sajan MP, et al.: Neuronal apoptosis linked to EgIN3 prolyl hydroxylase and familial pheochromocytoma genes: developmental culling and cancer. Cancer Cell 2005, 8:155-167.

\section{Pre-publication history}

The pre-publication history for this paper can be accessed here:

http://www.biomedcentral.com/1471-2350/10/34/pre pub

Publish with Bio Med Central and every scientist can read your work free of charge

"BioMed Central will be the most significant development for disseminating the results of biomedical research in our lifetime. "

Sir Paul Nurse, Cancer Research UK

Your research papers will be:

- available free of charge to the entire biomedical community

- peer reviewed and published immediately upon acceptance

- cited in PubMed and archived on PubMed Central

- yours - you keep the copyright

Submit your manuscript here:

http://www.biomedcentral.com/info/publishing_adv.asp 